\title{
Impact of risk factors on serum levels of vasoactive substances in patients with peripheral arterial occlusive disease at different Fontaine's stages
}

\author{
Sasa Dragic ${ }^{1,2}$, Danica Momcicevic ${ }^{2}$, Biljana Zlojutro², Milka Jandric ${ }^{2}$, Tijana Kovacevic ${ }^{3}$, \\ Vlado Djajic ${ }^{4}$, Aleksandar Gajic ${ }^{5}$, Goran Talic ${ }^{5}$, Pedja Kovacevic' \\ 'Medical Intensive Care Unit, University Clinical Centre of Republic of Srpska, Banja Luka, Republic of Srpska, \\ Bosnia and Herzegovina \\ ${ }^{2}$ Pan-European University „Apeiron“, College of Health Sciences, Banja Luka, Republic of Srpska, Bosnia and Herzegovina \\ ${ }^{3}$ Clinical Pharmacy, University Clinical Centre of Republic of Srpska, Banja Luka, Republic of Srpska, Bosnia and Herzegovina \\ ${ }^{4}$ Faculty of medicine, University of Banja Luka, Banja Luka, Republic of Srpska, Bosnia and Herzegovina \\ ${ }^{5}$ Institute for the Physical Medicine and Rehabilitation “Dr Miroslav Zotovic” Banja Luka, Republic of Srpska, \\ Bosnia and Herzegovina
}

\begin{abstract}
Introduction: There is a bulk of literature data on the physiological roles of nitric oxide (NO) and endothelin-I (ET-I), but many facts remain unknown, especially in certain diseases such as peripheral arterial disease. Material and methods: This is an observational cross-sectional study. The subjects were patients diagnosed with PAD. Serum levels of NO and ET-I were determined for all patients, and statistical data processing was performed according to the set goals.

Results: The study included 64 patients with mean age $60.2 \pm 12.7$ years, mostly in stage II PAD according to Fontain (46.9\%). Statistical analysis failed to determine a significant difference in serum NO or ET-I values with respect to disease stage, sex, and body mass index (BMI). Certain oscillations were found in the mean values of NO related to smoking and diabetes but without statistical significance. There were also oscillations in the values of ET-I, with higher levels found in women, smokers and non-diabetics in whom this difference reached statistical significance $(p=0.041)$.
\end{abstract}

Conclusion: Serum levels of NO and ET-I in this study show some causal relationship with certain risk factors for PAD such as diabetes and smoking, but additional research is needed to fully understand their effects and interactions.

Key words: local circulation, peripheral arterial disease, endothelin-I, nitric oxide

Acta Angiol 2020; 26, 3: 102-107

\section{Introduction}

The endothelium of blood vessels synthesizes a lot of different mediators that are involved in vasodilatation, vasoconstriction, adhesion, growth, differentiation, proliferation and other aspects of endothelial function that are responsible for cardiovascular homeostasis and health [I-3]. Endothelial dysfunction is characterized by imbalanced vasodilatation and vasoconstriction, elevated levels of reactive oxygen species and proinflammatory factors, as well as deficiency of nitric oxide bioavailability [3]. Endothelium dysfunction may result

Address for correspondence: Sasa Dragic, Medical Intensive Care Unit, University Clinical Centre of Republic of Srpska, Banja Luka, Republic of Srpska, Bosnia and Herzegovina, Dvanaest beba bb, 78000 Banja Luka, Bosnia and Herzegovina, e-mail: drdragics@gmail.com 
in the loss of important homeostatic functions, which, in turn, leads to various pathologies. For example, endothelial dysfunction is the initial stage in the pathogenesis of peripheral artery disease, cardiovascular disease, chronic venous disease, chronic kidney failure, cancer, infectious diseases, and obesity [4].

Endothelial cell in the walls of arterioles and small arteries synthetize a number of vasoactive substances, some of which are potent vasodilators, such as nitric oxide (NO), or potent vasoconstrictors, such as endothelin-I (ET-I) [5].

Nitric oxide is also considered to be responsible for platelet aggregation, non-adrenergic-non-cholinergic neurotransmission and cytotoxic reactions [6], while ET-I has a 100 times more potent vasoconstrictor effect than adrenaline, and can also have effects on muscle contractility, secretory activity, cell transport management, growth and proliferation as well as modulation of the immune response [7-10].

ET-I is inextricably linked to a number of vascular mediators, primarily NO, to which it acts as a natural counterpart. However, there is evidence that they do not have a simple opposite effect on the vascular system, but rather there is a complex system of coordinated cascade of reactions [ $1 \mathrm{I}, 12]$.

The dominant vasoconstrictor effect of ET-I is manifested through ET-A receptors, while the initial shortterm vasodilatating effect is explained by the autocrine feedback of ET-I through ET-B receptors on endothelial cell membranes, which promotes transient production of prostacyclin and NO which cause vasodilatation $[13,14]$. In pathophysiological conditions where the availability of $\mathrm{NO}$ is compromised, vasoconstrictor and other effects of ET-I such as proliferation and migration become disinhibited. This can lead to the development of a certain pathological process or worsening of the existing one. All the evidence suggests that balance among these mediators is crucial for preserving vascular function and that loss of balance between them leads to disruption or exacerbation of pre-existing vascular disease [I]

Homeostasis of endothelial vasoactive substances is disturbed in many diseases, and one of them is peripheral arterial disease (PAD). Most patients with PAD have impaired vascular function and vascular regulation, and the studies of homeostatic mechanisms involving these substances and their receptors are very actual.

\section{Material and methods}

\section{Study design and location}

The study was designed as an observational cross-sectional study and it was conducted in the period from January to July 2016 , during multimodal hospital treat- ment of patients diagnosed with PAD at the Department of Physical Medicine and Rehabilitation "Dr Miroslav Zotovic" Banja Luka — at the Center for Hyperbaric Medicine and Rehabilitation and Treatment of Chronic Wounds.

The study was approved by the Ethics Committee of the Institute for the Physical Medicine and Rehabilitation "Dr Miroslav Zotovic" Banja Luka (the number of agreement: 6947/13). The informed consent was signed by the patient or authorized representative of the patient. Measurements were performed at two separate certified laboratories.

\section{Patients}

Inclusion criteria for this study were age over 20 years, signed consent to participate in the study (informed consent), documented findings with a diagnosis of PAD, and data on the stage of Fontaine's disease. In relation to the classification of PAD according to Fontaine, the study included patients with stages II (intermittent claudication as the dominant symptom), III (pain at rest as the dominant symptom) and IV (the dominant finding is irreversible ischemia with necrosis and gangrene). Exclusion criteria were age less than 20 years, pregnancy and patients without established diagnosis of PAD. Patients were interviewed, and after signing informed consent, demographic data (gender and age), anthropometric data (height and weight from which BMI was calculated), and data on smoking status and a history of diabetes were recorded for each patient.

\section{Blood sampling}

Blood for analysis was obtained by venipuncture of the cubital vein. A total sample of 2 milliliters of blood was taken before initiating any therapeutic measures prescribed by hospital treatment at the same time each day (between 8 and 10 AM) before the start of any therapeutic procedures.

\section{Serum NO level measurement}

NO levels were determined by spectrophotometry using the Griess reagent (Griess method). Immediately after sampling, the samples were treated with $30 \%$ $\mathrm{ZnSO} 4$ to deproteinize the blood and release hemoglobin-bounded $\mathrm{NO}^{2-}$. It was then centrifuged for 10 minutes, and separated supernatants were stored in the freezer at $-80^{\circ} \mathrm{C}$. NO concentration was measured using the classical colorimetric Griess reaction, the conversion of $\mathrm{NO}^{2-}$ to $\mathrm{NO}^{2-}$ by elemental zinc followed by measuring $\mathrm{NO}^{2-}$ concentration. The concentration of $\mathrm{NO}$ (in $\mathrm{mmol} / \mathrm{L}$ ) was determined from a standard curve with known concentrations of $\mathrm{NaNO} 2$ (from $1.56-100 \mathrm{mmol} / \mathrm{L})$. Purified water with Griess reagent was used as a blank probe. The mean value of three 
consecutive measurement performed on the same sample was taken as the definitive level of NO. Intra and inter assay CV were 6.3 and 5.9\%, respectively.

\section{Serum ET-I level measurement}

Serum was separated from the whole blood using water bath at $37^{\circ} \mathrm{C}$, after which it was frozen at $-80^{\circ} \mathrm{C}$ until analysis. Determination of serum ET-I levels was performed with EIA methodology based on an immunometric assay, the so-called "Sandwich technique" using the Endothelin-I ELISA kit, IBL Hamburg, Germany. The concentration of ET-I is determined measuring the change in color intensity. This measurement was performed electronically using an ELISA reader (Elx 800 Universal Microplate Reader Biotek Instruments, INC) at a wavelength of $405 \mathrm{~nm}$. An automatic ELISA washer from the same manufacturer was used to rinse the plate. The standard curve was obtained from known ET-I activities within the kit. The values obtained are expressed in $\mathrm{pg} / \mathrm{ml}$. Since 8 standard probes were used to obtain the standard curve, with decreasing concentrations in the SI-S8 standards, the SI sample chamber contained a concentration of about $250 \mathrm{pg} /$ $/ \mathrm{mL}$, the next one $125 \mathrm{pg} / \mathrm{mL}$, and further $62.5 \mathrm{pg} / \mathrm{mL}$, $26.3 \mathrm{pg} / \mathrm{mL}$ and in each of the following two times less than in the previous one, while the S8 sample contained only diluted human plasma from the kit itself, with the manufacturer's guarantee that the concentration of ET-I was less than I.5 pg/mL. Thus, for the adsorbents obtained below the absorbance values for standard S8, we interpreted the serum ET-I levels of subjects below $1.5 \mathrm{pg} / \mathrm{mL}$ as expected (normal) values in potentially healthy subjects. For these adsorption findings, level of $1.5 \mathrm{pg} / \mathrm{mL}$ was noted in the table. The mean value of three consecutive measurement performed on the same sample was taken as the definitive level of ET-I. Intra- and inter-assay CVs were 5.9 and $6.2 \%$, respectively.

\section{Statistical analysis}

The obtained results were stored in table (MS Excel 2013), and the SPSS software (IBM Corp. Released 2012. IBM SPSS Statistics for Windows, Version 21.0. Armonk, NY: IBM Corp.) was used for all statistical analysis. Data were processed by standard statistical methods, both from the domain of descriptive statistics (basic descriptive measures: mean, mode, median, standard deviation) and from the area of statistical inference (Student's t test for small independent samples, Student's $t$ test for small dependent samples, $\chi^{2}$ test, ANOVA test). Values of $\mathrm{p}<0.05$ were considered statistically significant.
Table I. Descriptive parameters of studied patients

\begin{tabular}{|l|c|}
\hline Males & $n(\%)$ \\
\hline Age 20-29 years & $36(56.3)$ \\
\hline Age 30-39 years & $2(3.1)$ \\
\hline Age 40-49 years & $4(6.3)$ \\
\hline Age 50-59 years & $3(4.7)$ \\
\hline Age 60-69 years & $19(29.7)$ \\
\hline Age > 70 years & $25(39.0)$ \\
\hline Stage II PAD & $11(17.2)$ \\
\hline Stage III PAD & $30(46.9)$ \\
\hline Stage IV PAD & $21(32.8)$ \\
\hline Smokers & $13(28.3)$ \\
\hline Diabetes & $15(23)$ \\
\hline Body mass index $>24.9$ & $52(8 \mathrm{I})$ \\
\hline
\end{tabular}

\section{Results}

During the study period, a total of 64 patients ( 36 men and 28 women) treated at the Center for Hyperbaric Medicine and Rehabilitation and Treatment of Chronic Wounds were included using previously defined criteria. Patients' characteristics are shown in Table I.

Table 2 presents comparison of NO (mean values $\pm \mathrm{SD})(\mathrm{mmol} / \mathrm{L})$ and ET-I (mean values $\pm \mathrm{SD})(\mathrm{pg} /$ $/ \mathrm{mL}$ ) serum levels between different groups of studied patients. Patients were divided in groups according to presence of risk factors (stage of PAD, gender, smoking and diabetes).

Significantly higher NO concentrations were found in the age group 20-29 years compared to almost all other age groups using post hoc Tukey analysis [group $20-29$ (mean \pm SD) $41.45 \pm 16.7$ vs. group ${ }_{30-39(\text { mean } \pm S D)} 16 \pm 3.3$ $(p=0.01)$; group $_{20-29(\text { mean } \pm S D)} 4 \mathrm{l} .45 \pm 16.7$ vs. group 50-59(mean \pm SD) $19.07 \pm 7.82(p=0.09)$; group $20-29$ (mean \pm SD) $4 \mathrm{I} .45 \pm 16.7$ vs. group $60-69$ (mean \pm SD) $23.58 \pm 9.52$ $(p=0.05)$; group $20-29($ mean $\pm S D) 41.45 \pm 16.7$ vs. group $>70($ mean \pm SD) $19.19 \pm 6.74(p=0.01)]$.

The highest ET-I concentrations were detected in the age group 50-59 years but the difference between different age groups did not reach statistical significance.

\section{Discussion}

We showed in this study that patients with PAD have impaired homeostasis of the observed vasoactive substances. In addition to PAD, levels of vasoactives were also affected by smoking status and presence of diabetes. 
Table 2. Serum levels of NO and ET-I (mean value \pm SD) in regards to presence of risk factors

\begin{tabular}{|c|c|c|}
\hline & NO (mean value $\pm \mathrm{SD})(\mathrm{mmol} / \mathrm{L})$ & $\mathbf{p}$ \\
\hline Stage II/III/IV PAD & $21.9 \pm 9.6 / 20.0 \pm 6.9 / 23.5 \pm 11.5$ & $0.554^{*}$ \\
\hline Males/Females & $22.3 \pm 8.9 / 21.1 \pm 9.5$ & $0.604^{\#}$ \\
\hline $\mathrm{BMI} \leq 24.9 / \mathrm{BMI}>24.9$ & $23.9 \pm 12.4 / 20.6 \pm 7.3$ & $0.182^{\#}$ \\
\hline Smoker/Non-smoker & $19.6 \pm 7.1 / 22.3 \pm 9.8$ & $0.34 I^{\#}$ \\
\hline \multirow[t]{2}{*}{ Diabetes/No diabetes } & $20.9 \pm 8.0 / 24.8 \pm 13.2$ & $0.182^{\#}$ \\
\hline & ET-I (mean value $\pm \mathrm{SD})(\mathrm{pg} / \mathrm{mL})$ & $\mathbf{p}$ \\
\hline Stage II/III/IV PAD & $6.3 \pm 15.9 / 1.5 \pm 0.000 / 3.8 \pm 8.2$ & $0.343^{*}$ \\
\hline Males/Females & $1.50 \pm 0.000 / 6.48 \pm 15.37$ & $0.080^{\#}$ \\
\hline $\mathrm{BMI} \leq 24.9 / \mathrm{BMI}>24.9$ & $4.2 \pm 8.4 / 4.2 \pm 12.8$ & $0.998^{\#}$ \\
\hline Smoker/Non-smoker & $8.9 \pm 21.7 / 2.8 \pm 5.4$ & $0.075^{\#}$ \\
\hline Diabetes/No diabetes & $2.8 \pm 5.6 / 10.3 \pm 23.8$ & $0.04 I^{\#}$ \\
\hline
\end{tabular}

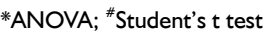

NO levels differed between patients in different stages of PAD but without statistical significance. The fact that PAD is basically an inflammatory process and that stimulation of endothelial procoagulant tissue factors, leukocyte adhesion molecules and chemotactic substances as well as endothelial NO synthase inhibitors leads to a decrease in NO production, our finding was contradictory [15].

We showed higher oscillations of ET-I concentrations between patients in different stages of PAD but without statistical significance. The predominance of ET-I vasoconstrictor effects was expected, but lower values were detected in more severe stages of the disease. The reason for this may be found in the chronic nature of the condition, as well as the involvement of other mechanisms and mediators [16-18].

When looking at demographic data we haven't found significant difference in NO levels between patients' groups, while ET-I levels were lower in male patients but without statistical significance. Data from the works of other authors on impact of gender on ET-I levels are very scarce.

Obesity as one of the risk factors for the development of metabolic syndrome was expressed through $\mathrm{BMI}$ and patients with $\mathrm{BMI}>24.9$ were classified as obese. The effect of hyperglycemia on blocking the function of endothelial NO synthetase and increasing the production of free radicals that interfere with vasodilatatory homeostasis has been known for some time [19], and in the light of these findings lower NO levels could be attributed to higher BMI. Elevated ET-I values were initially observed in obese patients, which was confirmed in experimental studies where higher expression of ET-A was demonstrated relative to ET-B receptors in adipose tissue [20, 21$]$. Our findings related to ET-I do not support these findings.

$A$ very significant finding of this study is that ET-I levels are higher and NO levels are lower in smokers, which is unequivocal evidence of the predominance of vasoconstrictor effects in smokers. Other authors state that cigarette smoking is a risk factor for vascular diseases, such as hypertension, atherosclerosis and aneurysm $[22,23]$. A crucial feature of smoking-induced vascular injury is endothelial dysfunction, defined as decreased nitric oxide bioavailability in the vascular wall [24]. Among studies that tested the effect of nicotine on NO-dependent endothelial relaxation, one stands out [25] which showed that cigarettes containing nicotine extract more severely damage the integrity of the endothelium compared to those that are nicotine free. Subsequent analyzes have shown that other components of tobacco smoke also damage NO homeostasis, although to a much greater extent if combined with nicotine [26-28].

A strong relationship between ET-I levels and smoking status (current smoker) was demonstrated in one 
large cohort study that monitored ET-I levels in healthy young adults where a link with global cardiovascular risks including smoking, blood pressure, and inflammation was demonstrated [29]. Additionally, smoking is thought to affect vascular tone via the endothelin system, moreover it is activated via ET-receptor pivotal protein kinases, such as mitogen-activated (MAP) kinases involved in important cell cycle and inflammatory cascades [30, 3I].

There is evidence that diabetes leads to the activation of alternative signaling pathways that stimulate cell growth and proliferation, thus stimulating the release of ET-I [32]. This has been confirmed by observations in animal models [33].

Limitations of this study are the inability to accurately determine the serum concentration of ET-I for serum values less than $1.5 \mathrm{pg} / \mathrm{mL}$ due to the limitations of the kit that was used. Also, one of the shortcomings is the lack of classification of smokers into categories according to the smoking pack years, and classification of diabetes according to the present complications. We also did not use ankle brachial index for determination of correlation between PAD and CAD like certain studies [34-36]. Additionally, we did not have control group of healthy subject.

\section{Conclusions}

Finally, the results of this study showed that $\mathrm{NO}$ and ET-I represent important factors in modeling the pathological process in PAD. The fact that the basic values of the examined vasoactive substances show oscillations depending on the presence of certain risk factors and comorbidities, gives us the right to consider them in one context as an etiological cause, and in another as a driver of the pathophysiological path for PAD.

\section{Conflict of interest}

None.

\section{References:}

I. Bourque SL, Davidge ST, Adams MA. The interaction between endothelin-I and nitric oxide in the vasculature: new perspectives. Am J Physiol Regul Integr Comp Physiol. 201 I; 300(6): RI288-RI295, doi: 10.1 I52/ajpregu.00397.2010, indexed in Pubmed: 21368267.

2. Matschke K, Jung F. Regulation of the myocardial microcirculation. Clin Hemorheol Microcirc. 2008; 39(I-4): 265-279, indexed in Pubmed: 18503135.

3. Sun HJ, Wu ZY, Nie XW, et al. Role of Endothelial Dysfunction in Cardiovascular Diseases: The Link Between Inflammation and Hydrogen Sulfide. Front Pharmacol. 2019; 10: 1568, doi: 10.3389/fphar.2019.01568, indexed in Pubmed: 32038245.
4. Stanek A, Fazeli B, Bartuś S, et al. The Role of Endothelium in Physiological and Pathological States: New Data. Biomed Res Int. 2018; 2018: 1098039, doi: 10.1155/2018/1098039, indexed in Pubmed: 30581842.

5. Stankevicius E, Kevelaitis E, Vainorius E, et al. [Role of nitric oxide and other endothelium-derived factors]. Medicina (Kaunas). 2003; 39(4): 333-34I, indexed in Pubmed: 1273890 I.

6. Giaid A, Saleh D. Reduced expression of endothelial nitric oxide synthase in the lungs of patients with pulmonary hypertension. N Engl J Med. 1995; 333(4): 214-221, doi: 10.1056/ NEJMI 99507273330403 , indexed in Pubmed: 7540722.

7. Herman WH, Simonson MS. Nuclear signaling by endothelin-I. J Biol Chem. 1995; 270: II654-6I.

8. Taylor C, Moncada S. Nitric oxide, cytochrome C oxidase, and the cellular response to hypoxia. Arteriosclerosis, Thrombosis, and Vascular Biology. 2010; 30(4): 643-647, doi: 10.1 161/atvbaha. 108.181628 .

9. Khimji AK, Rockey DC. Endothelin - biology and disease. Cell Signal. 2010; 22(1I): 1615-1625, doi: 10.1016/j.cellsig.2010.05.002, indexed in Pubmed: 20466059.

10. Krüger-Genge A, Blocki A, Franke RP, et al. Vascular endothelial cell biology: an update. Int J Mol Sci. 2019; 20(I8), doi: 10.3390/ ijms20 1844II, indexed in Pubmed: 31500313.

II. Black SM, Kumar S, Wiseman D, et al. Oxidative and nitrosative stress in pediatric pulmonary hypertension: roles of endothelin-I and nitric oxide. Vascul Pharmacol. 2006; 45(5): 308-316, doi: 10.1016/j.vph.2006.08.005, indexed in Pubmed: 17049313.

12. Pollock JS, Pollock DM. Endothelin and NOSI/nitric oxide signaling and regulation of sodium homeostasis. Curr Opin Nephrol Hypertens. 2008; 17(I): 70-75, doi: 10.1097/MNH.0b013e3282f34b02, indexed in Pubmed: 18090673.

13. Kester M, Simonson MS, McDermott RG, et al. Endothelin stimulates phosphatidic acid formation in cultured rat mesangial cells: role of a protein kinase C-regulated phospholipase D. J Cell Physiol. 1992; 150(3): 578-585, doi: 10.1002/jcp.1041500319, indexed in Pubmed: 1537886.

14. Ridker P, Cushman M, Stampfer M, et al. Plasma concentration of $C$-reactive protein and risk of developing peripheral vascular disease. Circulation. 1998; 97(5): 425-428, doi: 10.1161/01. cir.97.5.425.

15. Thorin E, Clozel M. The cardiovascular physiology and pharmacology of endothelin- I. Advances in Pharmacology. 2010: I-26, doi: 10.1016/b978-0-12-38506I-4.0000I-5.

16. Jain A, Coffey C, Mehrotra $V$, et al. Endothelin-I traps as a potential therapeutic tool: from diabetes to beyond? Drug Discov Today. 2019; 24(9): 1937-1942, doi: 10.1016/j.drudis.2019.07.008, indexed in Pubmed: 31394173 .

17. Weng YH. Alteration of nitric oxide gas on gene expression of endothelin-I and endothelial nitric oxide synthase by a timeand dose-dependent manner in human endothelial cells. The Chinese Journal of Physiology. 2009; 52(2): I-6, doi: 10.4077/ cjp.2009.amg085.

18. Goel A, Su B, Flavahan S, et al. Increased endothelial exocytosis and generation of endothelin-I contributes to constriction of aged arteries. Circ Res. 2010; 107(2): 242-25I, doi: 10.1161/ CIRCRESAHA. 109.210229, indexed in Pubmed: 20522806.

19. Veves A, Akbari CM, Primavera J, et al. Endothelial dysfunction and the expression of endothelial nitric oxide synthetase in diabetic neuropathy, vascular disease, and foot ulceration. 
Diabetes. 1998; 47(3): 457-463, doi: 10.2337/diabetes.47.3.457, indexed in Pubmed: 9519754.

20. Eriksson A, Harmelen Vv, Stenson BM, et al. Endothelin-I stimulates human adipocyte lipolysis through the ETA receptor. International Journal of Obesity. 2008; 33(I): 67-74, doi: 10.1038/ ijo.2008.212.

21. van Harmelen V, Eriksson A, Aström G, et al. Vascular peptide endothelin-I links fat accumulation with alterations of visceral adipocyte lipolysis. Diabetes. 2008; 57(2): 378-386, doi: 10.2337/db07-0893, indexed in Pubmed: $180254 \mid 3$.

22. Katsiki N, Papadopoulou SK, Fachantidou Al, et al. Smoking and vascular risk: are all forms of smoking harmful to all types of vascular disease? Public Health. 2013; 127(5): 435-44I, doi: 10.1016/j.puhe.2012.12.021, indexed in Pubmed: 23453194.

23. Li J, Cui R, Eshak ES, et al. for CIRCS investigators. Association of cigarette smoking with radial augmentation index: the Circulatory Risk in Communities Study (CIRCS). Hypertens Res. 2018; 4I(I2): 1054-1062, doi: 10.1038/s41440-018-0106-5, indexed in Pubmed: 30333520.

24. Messner B, Bernhard D. Smoking and cardiovascular disease: mechanisms of endothelial dysfunction and early atherogenesis. Arterioscler Thromb Vasc Biol. 2014; 34(3): 509-515, doi: 10.1 I6I/ATVBAHA. I13.300156, indexed in Pubmed: 24554606.

25. Park JM, Chang KH, Park KH, et al. Differential effects between cigarette total particulate matter and cigarette smoke extract on blood and blood vessel. Toxicol Res. 2016; 32(4): 353-358, doi: 10.5487/TR.2016.32.4.353, indexed in Pubmed: $278 \mid 8738$.

26. Shimosato T, Geddawy A, Tawa M, et al. Chronic administration of nicotine-free cigarette smoke extract impaired endothelium-dependent vascular relaxation in rats via increased vascular oxidative stress. J Pharmacol Sci. 2012; II8(2): 206-214, doi: 10.1254/jphs. I I 187fp, indexed in Pubmed: 22302022.

27. Carlo WF, Villamor E, Ambalavanan N, et al. Chronic exposure to cigarette smoke extract impairs endothelium-dependent relaxation of chicken embryo pulmonary arteries. Biol Neonate. 200I; 80(3): 247-250, doi: 10.1159/000047I5I, indexed in Pubmed: II58599I.
28. Ota $\mathrm{Y}$, Kugiyama K, Sugiyama S, et al. Impairment of endothelium-dependent relaxation of rabbit aortas by cigarette smoke extract--role of free radicals and attenuation by captopril. Atherosclerosis. 1997; 131(2): 195-202, doi: 10.1016/s00219150(97)06106-6, indexed in Pubmed: 9199272.

29. Bossard M, Pumpol K, van der Lely S, et al. Plasma endothelin-I and cardiovascular risk among young and healthy adults. Atherosclerosis. 2015; 239(I): 186-191, doi: 10.1016/j.atherosclerosis.20I4. I2.06I, indexed in Pubmed: 25617859.

30. Hansson GK. Inflammation, atherosclerossis and coronary arthery disesae. N Engl J Med. 2005; 352: 1685-1695.

31. Haak T, Jungmann E, Raab C, et al. Elevated endothelin-I levels after cigarette smoking. Metabolism. 1994; 43(3): 267-269, doi: 10.1016/0026-0495(94)9009I-4, indexed in Pubmed: 81 39472.

32. Cao L, Zhang Y, Cao YX, et al. Cigarette smoke upregulates rat coronary artery endothelin receptors in vivo. PLoS One. 2012; 7(3): e33008, doi: 10.1371/journal.pone.0033008, indexed in Pubmed: 224I 2974.

33. Ferri C, Carlomagno A, Coassin S, et al. Circulating endothelin-I levels increase during euglycemic hyperinsulinemic clamp in lean NIDDM men. Diabetes Care. 1995; 18(2): 226-233, doi: 10.2337/diacare. 18.2.226, indexed in Pubmed: 7729302.

34. Sarangi S, Srikant B, Rao DV, et al. Correlation between peripheral arterial disease and coronary artery disease using ankle brachial index-a study in Indian population. Indian Heart J. 2012; 64(I): 2-6, doi: 10.1016/50019-4832(12)60002-9, indexed in Pubmed: 22572416.

35. Wojtasik-Bakalarz J, Ruzsa Z, Rakowski T, et al. Impact of coronary artery disease and diabetes mellitus on the long-term follow-up in patients after retrograde recanalization of the femoropopliteal arterial region. J Diabetes Res. 2019; 2019: 6036359, doi: 10.1 155/2019/6036359, indexed in Pubmed: 31049356.

36. Myslinski W, Stanek A, Feldo M, et al. Ankle-brachial index as the best predictor of first acute coronary syndrome in patients with treated systemic hypertension. Biomed Res Int. 2020; 2020: 6471098, doi: 10.1155/2020/647/098, indexed in Pubmed: 32724805 . 